theory in one respect especially. If the visiting star is greater than the companion of the sun, the conditions would obviously be more favourable, but, on the whole, it seems extremely doubtful if an expla. nation will be found along these lines. Dr. Davidson is of opinion that some much simpler explanation, not demanding so many ad hoc assumptions, would be forthcoming, but this might be a long way off yet.

In conclusion, Dr. Davidson referred to the new satellites of Jupiter and to the fact that Mr. J. Miller had predicted a missing satellite (NATURE, Feb. 5, p. 245). Unfortunately, satellite $\mathrm{x}$, for which an orbit had been computed, did not fit into the place predicted for it, as it was 7 million miles from Jupiter. He felt, however, that there was a space about $2 \frac{1}{2}$ million miles from Jupiter in which a satellite would some day be discovered. The fact that satellites vi, vii, and $x$ are moving in similar orbits at nearly the same mean distances from their primary provides another problem for the cosmogonist. Perhaps a shoal of minute bodies occupies this region, but naturally one can only conjecture on such matters.

At the close of the address, Dr. Davidson vacated the presidential chair, which was then taken by $\mathrm{Mr}$. B. M. Peek, the newly elected president.

\title{
Removal of Sulphur Acids from Flue Gases
}

\begin{abstract}
T Great Britain there is manufactured annually about one million tons of sulphuric acid, but a quantity of sulphur oxides much greater than this is discharged into the atmosphere by the combustion of coal. In the last ten years, it has become possible to reduce atmospheric pollution from this source. The concentration of sulphur oxides in chimney gases is very low and so long as fuel-consuming units were small and scattered, the resulting damage was relatively inconspicuous. Moreover, any effective process for desulphurizing the gas would have been prohibitive in cost. Engineers limited their efforts to reducing the visible pollution by smoke and grit.
\end{abstract}

Technical developments in the generation of electricity compelled attention to the problem of cleaning flue gas. Mechanical stoking made it possible to burn fine coal at high rates of combustion and caused the discharge of much grit and dust into the atmosphere. The introduction of pulverized fuel accentuated the grit nuisance. Economy of steam production and power generation was secured by working in ever larger units and the need for reducing the high cost of distributing electricity required that these units should be installed near the load. The result has been the erection of huge coal burning units using inferior coal in large centres of population. With the project to erect the generating station at Battersea, the danger of discharging large quantities of sulphur acids into the heart of London was recognized, and the London Power Company was compelled to render its chimney gases innocuous before passing into the air. Now the concentration of coal burning into large units, while increasing the local intensity of atmospheric pollution, eased the technical problem of designing and operating economic processes of sulphur removal. In a relatively short time, the Battersea station was discharging into the air, flue gases almost free from sulphur. The gases, before entering the chimney, were washed with large volumes of Thames water to which lime was added and the clarified effluent returned to the river.

When the Fulham Power Station came to be enlarged, the authorities were able to insist that a similar standard of purity should be maintained; but in addition, that no effluent should be returned to the Thames, lest the alkalinity of the river water, already diminished by the Battersea plant, should be destroyed. The very existence of the Fulham plant was thus dependent on devising a process which made no liquid effluent. The wash liquor would inevitably become saturated with salts which must be removed as fast as made. The salt in this case was calcium sulphate, which is prone to form a troublesome scale on surfaces and in a continuous process liable to block the plant.

In an address delivered at a recent meeting of the London Section of the Society of Chemical Industry, Dr. R. Lessing described the course of experiments which showed how the salt could be removed without scale formation. Calcium sulphate solutions can persist in a super-saturated state; but this condition can be prevented if the wash liquor contains sufficient $\mathrm{CaSO}_{4} \cdot 2 \mathrm{H}_{2} \mathrm{O}$ on suspension. It was found possible to define conditions under which the flue gases could be washed continuously with a liquor, containing in suspension about 10 per cent of $\mathrm{CaSO}_{4}$ and working in a closed cycle. Water removed by evaporation up the chimney was replaced and fresh lime was added to replace that removed by precipitation of lime salts. An essential feature in the cycle was a 'delay' tank where the 'desupersaturation' of the liquor could proceed to a point where deposition of scale in the plant would not occur.

This process has now been in operation at Fulham and elsewhere long enough to leave no doubt that gases can be discharged from chimneys practically free from sulphur acids without the production of a liquid effluent. An important advantage of a washing process is the simultaneous removal of grit. Mechanical methods of removing grit are only partially successful. The electrostatic precipitator can retain grit almost completely, but allows acid gases to pass into the air. Moreover, the electrostatic precipitator is not certain under overload conditions such as arise when "soot blowing" is in progress.

The cost of sulphur extraction during the first year's working at Fulham was $0.0144 d$. per unit, and will doubtless be reduced with further experience. This may be a price well worth paying to reduce the damage due to sulphur in urban atmosphere. Dr. Lessing said that the washing of the chimney gases at Battersea and Fulham would eventually mean a reduction of sulphur pollution in the London area amounting to ten per cent. This shows the importance of this striking success of chemical engineering.

H. J. HodsmaN. 